\title{
PRKDC regulates chemosensitivity and is a potential prognostic and predictive marker of response to adjuvant chemotherapy in breast cancer patients
}

\author{
GANG SUN, LE YANG, CHAO DONG, BIN MA, MEIHUI SHAN and BINLIN MA \\ Department of Breast and Head \& Neck, The Affiliated Cancer Hospital of Xinjiang Medical University, \\ Urumqi, Xinjiang 830011, P.R. China
}

Received October 10, 2016; Accepted April 5, 2017

DOI: $10.3892 /$ or.2017.5634

\begin{abstract}
DNA-dependent kinase catalytic subunit(DNA-PKcs) is a critical component of DNA repair machinery and is found to be up- or down-regulated in different cancer types. However, its clinical significance in breast cancer remains unclear. To this end, quantitative PCR was performed to measure PRKDC expression level in 59 pairs of breast cancer tissues and the nontumor adjacent tissues (NATs). The correlation between PRKDC expression and overall survival (OS) as well as the prognostic value of PRKDC were analyzed. In vitro and in vivo effects of PRKDC on chemosensitivity were evaluated in MCF-7 cells. We found that PRKDC expression was significantly increased in breast cancer tissue samples compared with NATs. High PRKDC expression was associated with higher tumor grade $(\mathrm{P}=0.001)$, positive lymph node metastasis $(\mathrm{P}=0.0357)$ and chemoresistance $(\mathrm{P}=0.0006)$. Furthermore, PRKDC expression was significantly correlated with $\mathrm{OS}$ in breast cancer patients with $(0.0101)$ or without $(\mathrm{P}=0.0216)$ receiving chemotherapy. PRKDC was an independent prognostic factor of OS in breast cancer $(\mathrm{P}=0.022$, hazard ratio $=2.69,95 \%$ confidence interval: 1.81-3.84). Moreover, downregulation of PRKDC sensitized MCF-7 cells to chemo-drugs both in vitro and in a xenografted mouse model. Collectively, our study demonstrated that PRKDC is a prognostic biomarker for chemoresistance in breast cancer patients.
\end{abstract}

\section{Introduction}

Breast cancer is the most common type of tumor among women and is the second leading cause of cancer-related mortality worldwide. It is estimated that, in 2016, approximately 250,000 new cases of breast cancer will be diagnosed and 40,890 deaths will result from breast cancer (1). Breast cancer is regarded as a systemic disease, with micrometastatic

Correspondence to: Dr Binlin Ma, Department of Breast and Head \& Neck, The Affiliated Cancer Hospital of Xinjiang Medical University, No. 789 Suzhou East Road, Urumqi, Xinjiang 830011, P.R. China

E-mail: binlinma@gmail.com

Key words: breast cancer, PRKDC, chemoresistance, biomarker involvement at diagnosis in many patients. Although targeted therapies, including hormonal therapy in hormone receptorpositive and trastuzumab therapy in human epidermal growth factor receptor 2 (HER2)-positive patients are well established, chemotherapy remains an important mainstay in systemic treatment, especially in patients with high risk of relapse (2-4). Anthracycline-based chemotherapy regimens with the addition of taxanes into chemotherapy has improved survival outcome in the adjuvant setting (5). Unfortunately, long-term adverse effects and chemoresistance, pose challenges to further improving the efficacy of adjuvant breast cancer chemotherapy (6). Therefore, there is an urgent need to identify new reliable predictive biomarkers for chemosensitivity in breast cancer to improve disease management and patient survival.

PRKDC is a nuclear protein serine/threonine kinase that is activated upon association with DNA (7). It is a critical component of DNA repair machinery that plays a pivotal role in the DNA damage response (DDR), primarily double stranded break (DSB) response, and maintenance of genomic stability (8). In response to DSB formation, PRKDC is recruited to DSBs by the $\mathrm{Ku} 70 / 80$ heterodimer where it is rapidly activated after phosphorylation at multiple serine and threonine residues (9). Both aberrant expression or genetic mutations of PRKDC have been observed in various cancer types or pre-malignant cells, indicating that PRKDC may have paradoxically opposing roles in carcinogenesis, depending on the cell context or the tissue type (9-11). Moreover, due to its role in DDR, increased activity of PRKDC has been found to be associated with resistance to chemotherapeutic drugs and radiotherapy in glioma cells and oral squamous cell carcinoma, respectively $(12,13)$. Therefore, it is plausible to hypothesize that inhibitors of PRKDC might be useful in sensitizing cancer cells to chemotherapy and radiotherapy $(9,13)$.

In the present study, we evaluated the expression level of PRKDC in breast cancer patients receiving NAC and explored its potential as a prognostic biomarker as well as predictor of chemosensitivity in breast cancer.

\section{Materials and methods}

Patient and tissue samples. This study used archived material from Affiliated Cancer Hospital of Xinjiang Medical 
University admitted between March 2011 and December 2015, including breast cancer tissue samples from patients with stage IIIA-C disease for whom matching biopsies were available for pathological and immunohistochemical analysis. All tissues were immediately snap-frozen in liquid nitrogen and stored at $-80^{\circ} \mathrm{C}$ until use. The patients with any other tumor were excluded from the study. A total of 159 breast cancer tissues and 59 matched non-tumor adjacent tissues (NATs) were examined in the study. None of the subjects had received any therapeutic procedures prior to this study, including surgery, chemotherapy, and radiotherapy. In addition, a total of 89 patients who received six cycles of an anthracycline based-therapy (FEC: 5 -fluorouracil (5-FU) $500 \mathrm{mg} / \mathrm{m}^{2}$, epirubicin $75-100 \mathrm{mg} / \mathrm{m}^{2}$, cyclophosphamide $500 \mathrm{mg} / \mathrm{m}^{2}$, on day 1 of a 21-day cycle) were also included. All patients underwent surgery (mastectomy and axillary node clearance) 4 weeks after the last cycle of chemotherapy, followed by radiotherapy to the chest wall. The pathological complete response (pCR) was defined as the absence of any residual invasive carcinoma at both the primary site and in axillary lymph nodes. Patients with $\mathrm{pCR}$ were defined as responders whereas others were defined as non-responders. The prognosis was evaluated in all breast cancer patients in April 2015. Overall survival was defined as the time from cancer onset until death or by censoring at the last follow-up date. The study was approved by Affiliated Cancer Hospital of Xinjiang Medical University, and informed consent was obtained from all patients.

Total RNA extraction. Tissue sections were minced with scissors into small fragments $\left(1-2 \mathrm{~mm}^{3}\right)$ and homogenized with TRIzol $^{\mathrm{TM}}$ reagent (Takara Bio, Inc., Otsu, Japan). Chloroform (200 $\mu$ l; Sigma-Aldrich, Santa Clara, CA, USA) was added to the TRIzol homogenate. The preparations were then centrifuged at $12,000 \mathrm{x} \mathrm{g}$ for $15 \mathrm{~min}$ at $4^{\circ} \mathrm{C}$, and the upper aqueous layer was transferred to a clean Eppendorf tube, containing an equal volume of isopropanol (Sigma-Aldrich). The mixed suspensions were centrifuged at $12,000 \mathrm{x} \mathrm{g}$ for a further $15 \mathrm{~min}$ at $4^{\circ} \mathrm{C}$. The precipitations were then collected. After washing with 70\% ethanol, total RNA was dissolved in RNase-free water and the quality of RNA was evaluated by gel electrophoresis. RNA concentrations were measured by optical density (260 nm, Q5000, Quawell, San Jose, CA, USA) and the preparations stored at $-80^{\circ} \mathrm{C}$ for subsequent analysis.

$R T-q P C R$ analysis. cDNA was reverse transcribed on the Bio-Rad S1000 Thermal Cycler (Bio-Rad Laboratories, Hercules, CA, USA) using oligo (dT) as primers. Briefly, the total RNA $(1 \mu \mathrm{g})$ from each sample was reverse transcribed in a $20 \mu \mathrm{l}$ reaction volume, containing $0.5 \mu \mathrm{g}$ of oligo (dT) and 200 units M-MLV (MBI Fermentas, Vilnius, Lithuania). All samples were amplified in triplicate under the following conditions: $95^{\circ} \mathrm{C}$ for $2 \mathrm{~min}, 35$ cycles of $95^{\circ} \mathrm{C}$ for $15 \mathrm{sec}, 60^{\circ} \mathrm{C}$ for $30 \mathrm{sec}$ and $72 \mathrm{C}$ for $20 \mathrm{sec}$. $\mathrm{qPCR}$ reaction was performed on the Bio-Rad C1000 Real-time fluorescence thermal cycler (Bio-Rad Laboratories), using the following cycling conditions: Initiation at $95^{\circ} \mathrm{C}$ for $10 \mathrm{~min}$; amplification for 35 cycles, with denaturation at $95^{\circ} \mathrm{C}$ for $30 \mathrm{sec}$; annealing at $56^{\circ} \mathrm{C}$ for $30 \mathrm{sec}$; and elongation at $72^{\circ} \mathrm{C}$ for $30 \mathrm{sec}$. A final extension at $72^{\circ} \mathrm{C}$ was performed for $10 \mathrm{~min}$. GAPDH mRNA level was used for normalization.

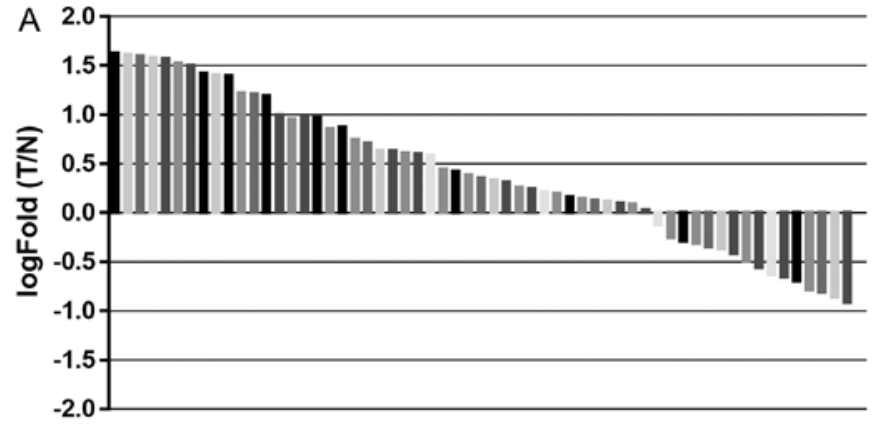

B

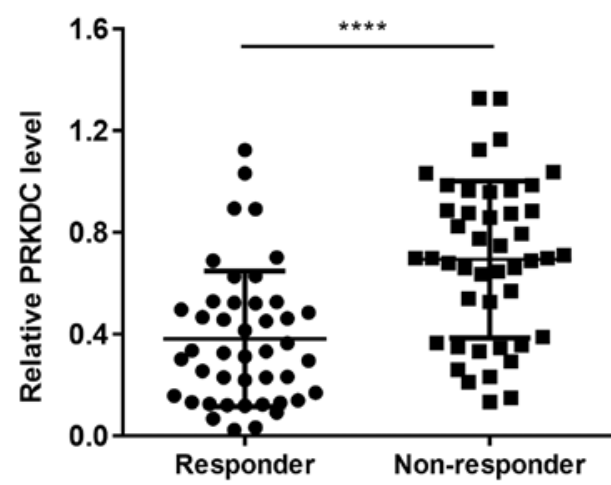

Figure 1. PRKDC expression levels in breast cancer tissue samples. (A) Histogram of PRKDC mRNA expression in 59 breast cancer patients. The relative expression in each patient was presented as the ratio of $\mathrm{T}$ (tumour tissue)/N (normal tissue). (B) Quantitative PCR analysis of relative PRKDC expression in tissue samples from breast cancer patients who are responders $(n=44)$ or non-responders $(n=45)$ to NAC. Data represent mean \pm SD ${ }^{* * * * *} \mathrm{P}<0.0001$.

Chemosensitivity assay. Cells were seeded at a density of $5 \times 10^{3}$ cells/well in 96-well microtiter plates and allowed to attach overnight. Chemo drugs were then added and cultured for an additional $72 \mathrm{~h}$. Cell viability was assessed using CellTiter-Glo ${ }^{\circledR}$ assay (Promega, Madison, WI, USA). Each value was normalized to cells treated with DMSO and the $\mathrm{IC}_{50}$ values are calculated using Graphpad Prism software.

Viral transductions and stable selections. For lentivirus production, $1 \mu \mathrm{g}$ of shPRKDC (Origene) together with $1 \mu \mathrm{g}$ of helper plasmids $(0.4 \mu \mathrm{g}$ pMD2G and $0.6 \mu \mathrm{g}$ psPAX2) were transfected into 293FT cells with Effectene reagent (Qiagen, Valencia, CA, USA). Viral supernatants were collected $48 \mathrm{~h}$ after transfections and cleared through a $0.45-\mu \mathrm{m}$ filter. Cells were infected with viral supernatants containing $4 \mu \mathrm{g} / \mathrm{ml}$ polybrene (Sigma, St. Louis, MO, USA) and selected with puromycin for 7 days.

Immunohistochemistry (IHC) staining. The paraffin-embedded sections were subjected to antigen retrieval by heating the slides in a microwave at $100^{\circ} \mathrm{C}$ for $10 \mathrm{~min}$ in $0.1 \mathrm{M}$ citric acid buffer ( $\mathrm{pH}$ 6.0), and then incubated with corresponding antibodies at $4^{\circ} \mathrm{C}$ overnight. After secondary antibody incubation at room temperature for $1 \mathrm{~h}$, the slides were developed in $0.05 \%$ diaminobenzidine containing $0.01 \%$ hydrogen peroxidase. For negative controls, specific antibodies were replaced with normal goat serum by co-incubation at $4^{\circ} \mathrm{C}$ overnight preceding the immunohistochemical staining procedure. 
A

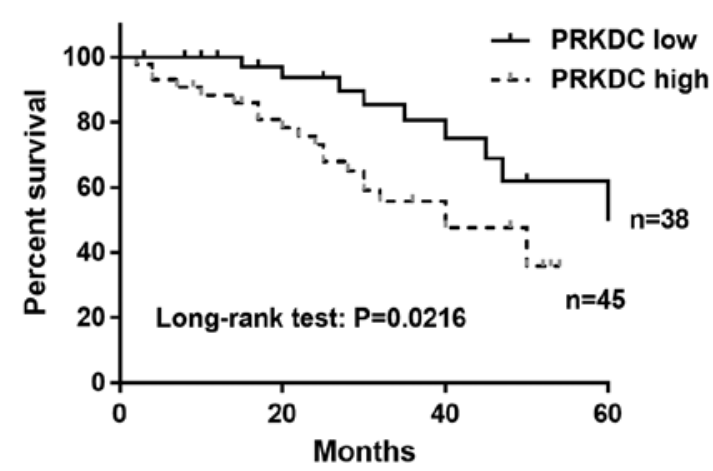

B

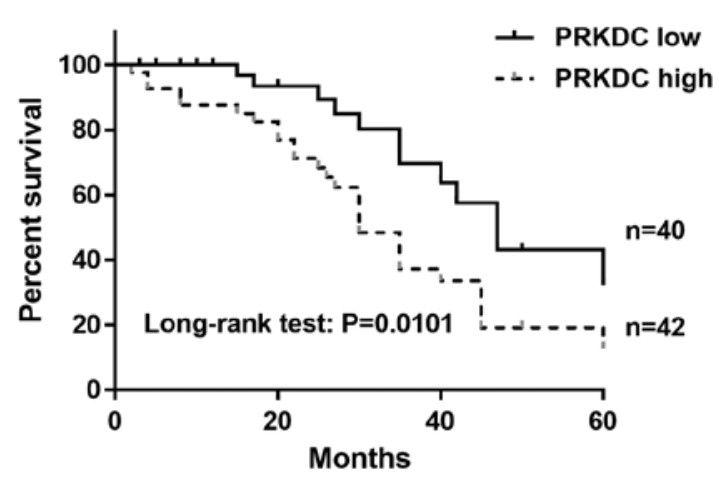

Figure 2. Correlation between PRKDC expression and OS in breast cancer patients with or without receiving NAC. (A) Kaplan Meier OS of breast cancer patients without receiving NAC. Patients with high PRKDC expression had a shorter survival $(\mathrm{P}=0.0216)$. (B) Kaplan Meier OS of breast cancer patients receiving NAC. Patients with high PRKDC expression had a shorter survival $(\mathrm{P}=0.0101)$.

Xenograft experiments. All animal experiments were approved by Institutional Animal Care and Use Committee of National Cancer Center. MCF-7 cells (3x10 $10^{6}$ cells/ injection) expressing control shRNA or PRKDC shRNA-2 were subcutaneously injected into both flanks of 5-weekold female nude mice. Vehicle or 5 -FU $(25 \mathrm{mg} / \mathrm{kg})$ was injected i.p. into mice daily for 12 days. Tumor volumes were measured using caliper and determined by a formula [volume $=\left(\right.$ length $\mathrm{x}$ width $\left.{ }^{2}\right) / 2$ ] from day 6 to day 18 postimplantation. The results were expressed as mean tumor volumes with SD.

Statistical analysis. For cell culture and mouse experiments, quantitative data are expressed as mean \pm SD. Statistical significance was assessed by the Student's t-test. Differences were considered to be significant when $\mathrm{P}<0.05$. For patient sample data, statistical analysis was performed using IBM SPSS Statistics version 16 (SPSS Inc., Chicago, IL, USA) and GraphPad Prism v5.0 (Graphpad Software Inc.). The Wilcoxon test was used to compare PRKDC expression in paired tumor tissue samples and NATs. The Mann-Whitney U test was used to perform statistical analysis of PRKDC mRNA level between unpaired groups. The Pearson's Chi-squared test and Fisher's exact test were used to evaluate the association between tissue PRKDC mRNA level and clinicopathological parameters. In addition, survival curves were constructed with the Kaplan-Meier method and compared using log-rank test. Cox proportional hazards regression analysis was used for univariate and multivariate analyses of prognostic values. P-value of two-sided $<0.05$ was considered statistically significant.

\section{Results}

PRKDC expression is upregulated in breast cancer tissues. The expression level of PRKDC was evaluated in 59 pairs of breast cancer tissues and the NATs using quantitative real-time PCR. The relative mean expression value of PRKDC mRNA in cancer tissues $(4.25 \pm 2.68$, normalized to GAPDH gene expression) was significantly higher than that $(1.96 \pm 1.42)$ in the corresponding normal tissues $(\mathrm{P}<0.010)$. Expression fold changes above 1 was considered as upregulation of PRKDC
mRNA in the cancer tissues. The results revealed that $72.9 \%$ (43/59) of breast cancer tissues expressed a higher level of PRKDC compared with the matched normal tissues. We also measured the PRKDC expression levels in tissue samples from 44 breast cancer patients who responded to NAC and 45 patients who did not. We found that the expression levels of PRKDC were significantly higher in the non-responder group than the responder group $(\mathrm{P}<0.0001)$ (Fig. 1B).

Association between tissue PRKDC expression level and clinicopathological factors or chemotherapy response. The correlation between PRKDC expression level and clinicopathological factors or chemotherapy response was assessed using $\chi^{2}$ test. As shown in Table I, a total of 62 of $102(60.7 \%)$ patients who were Grade II or III had significantly higher expression level of PRKDC than Grade I patients $(\mathrm{P}=0.001)$. We detected high PRKDC level in patients who were lymph node metastasis positive $(\mathrm{P}=0.0357)$. High $\mathrm{PRKDC}$ expression level was observed in $34 \%$ and $71.1 \%$ of patients who were responders or non-responders to neoadjuvant chemotherapy (NAC), respectively $(\mathrm{P}=0.0006)$. However, no significant correlation was observed between PRKDC expression levels and age $(P=0.1541)$, tumor size $(P=0.8736)$, tumor stage $(\mathrm{P}=0.3691)$, ER status $(\mathrm{P}=0.1354), \mathrm{PR}$ status $(\mathrm{P}=0.191)$ or Her-2 status $(\mathrm{P}=0.4189)$.

High expression of PRKDC predicts poor prognosis in breast cancer patients with or without receiving NAC. Univariate and multivariate survival analyses were performed to examine the effects of clinicopathological factors and PRKDC expression on prognosis in patients receiving NAC. As shown in Table II, lymph node metastasis $(\mathrm{P}=0.044)$, tumor grade $(\mathrm{P}=0.038)$, PRKDC expression $(\mathrm{P}=0.011)$ and response to NAC $(\mathrm{P}=0.008)$ were significantly associated with overall survival (OS). Tumor grade $(\mathrm{P}=0.037, \mathrm{HR}=2.16,95 \%$ confidence interval: $1.35-3.04)$, PRKDC expression $(\mathrm{P}=0.022, \mathrm{HR}=2.69,95 \%$ confidence interval: $1.81-3.84)$ and response to NAC $(\mathrm{P}=0.014, \mathrm{HR}=3.96$, 95\% confidence interval: $2.61-5.47)$ were independent predictors of OS in these patients (Table II).

A survival analysis of OS was performed in patients with or without NAC treatment to determine whether PRKDC expression level can predict prognosis. The estimated Kaplan-Meier 
Table I. Correlation between tissue PRKDC expression level and clinicopathological factors or chemosensitivity.

\begin{tabular}{|c|c|c|c|c|}
\hline Characteristics & $\begin{array}{l}\text { No. of } \\
\text { patients }\end{array}$ & $\begin{array}{c}\text { PRKDC } \\
\text { low } \\
\text { expression }\end{array}$ & $\begin{array}{c}\text { PRKDC } \\
\text { high } \\
\text { expression }\end{array}$ & P-value \\
\hline Age (years) & & & & 0.1541 \\
\hline$\leq 50$ & 117 & 57 & 60 & \\
\hline$>50$ & 42 & 26 & 16 & \\
\hline Tumor size $(\mathrm{cm})$ & & & & 0.8736 \\
\hline$\leq 2$ & 83 & 39 & 44 & \\
\hline$>2$ & 76 & 34 & 42 & \\
\hline Tumor stage & & & & 0.3691 \\
\hline $\mathrm{I}, \mathrm{II}$ & 118 & 62 & 56 & \\
\hline III & 41 & 25 & 16 & \\
\hline Tumor grade & & & & $0.0010^{\mathrm{a}}$ \\
\hline I & 57 & 38 & 19 & \\
\hline II, III & 102 & 40 & 62 & \\
\hline Lymph node metastasis & & & & $0.0357^{\mathrm{a}}$ \\
\hline Negative & 65 & 40 & 25 & \\
\hline Positive & 94 & 41 & 53 & \\
\hline ER status & & & & 0.1354 \\
\hline Negative & 56 & 23 & 33 & \\
\hline Positive & 103 & 56 & 47 & \\
\hline PR status & & & & 0.1910 \\
\hline Negative & 74 & 50 & 24 & \\
\hline Positive & 85 & 48 & 37 & \\
\hline Her-2 status & & & & 0.4189 \\
\hline Negative & 96 & 48 & 48 & \\
\hline Positive & 63 & 27 & 36 & \\
\hline Clinical response to NAC & & & & $0.0006^{\mathrm{a}}$ \\
\hline Responder & 44 & 29 & 15 & \\
\hline Non-responder & 45 & 13 & 32 & \\
\hline
\end{tabular}

${ }^{\text {aP }}<0.05$, statistical significance. ER, estrogen receptor; $\mathrm{PR}$, progesterone receptor.

OS curves showed that high expression of PRKDC was significantly correlated with poor OS in patients without receiving NAC $(\mathrm{P}=0.0216)$ (Fig. 2A). In patients receiving NAC treatment, the OS was significantly worse in patients with high levels of PRKDC $(\mathrm{P}=0.0101)$ with a median survival of 30 months (Fig. 2B). These results indicate that high PRKDC expression was associated with poor OS in patients with or without NAC treatment and was an independent prognostic factor.

Downregulation of PRKDC sensitizes breast cancer cells to chemo-drugs in vitro and in vivo. To examine the regulatory role of PRKDC in chemoresistance in breast cancer cells, we generated stable PRKDC knockdown MCF-7 cell lines using two independent shRNAs targeting PRKDC. The knockdown efficiency was confirmed by qPCR (Fig. 3) and MCF-7 cells

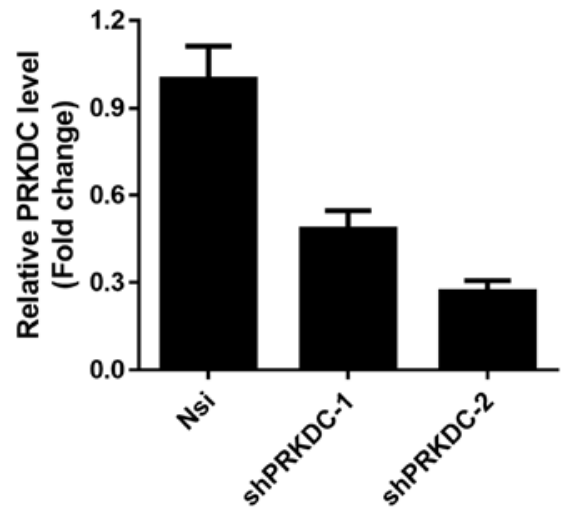

Figure 3. qPCR analysis of knockdown efficiency in MCF-7 cells expressing non-silencing shRNA or 2 shRNAs against PRKDC.

Table II. Univariate and multivariate analysis of factors associated with overall survival for patients with breast cancer (stage IIIA-C) who received NAC prior to surgery.

\begin{tabular}{lcccc}
\hline & & \multicolumn{2}{c}{ Multivariate } \\
\cline { 4 - 5 } Variables & \begin{tabular}{c} 
Univariate \\
\cline { 3 - 4 } P-value
\end{tabular} & HR & $95 \%$ CI & P-value \\
\hline Tumor size & 0.446 & & NA \\
Tumor stage & 0.645 & NA \\
Lymph node metastasis & 0.297 & & NA \\
Tumor grade & $0.044^{\mathrm{a}}$ & & 0.079 \\
ER status & $0.038^{\mathrm{a}}$ & 2.16 & $1.35-3.04$ & $0.037^{\mathrm{a}}$ \\
PR status & 0.058 & & & $\mathrm{NA}$ \\
Her-2 status & 0.112 & & $\mathrm{NA}$ \\
PRKDC expression & 0.265 & & & NA \\
Positive vs. negative & & & & \\
Response to NAC & $0.011^{\mathrm{a}}$ & 2.69 & $1.81-3.84$ & $0.022^{\mathrm{a}}$ \\
Non-responder vs. responder & $0.008^{\mathrm{a}}$ & 3.96 & $2.61-5.47$ & $0.014^{\mathrm{a}}$
\end{tabular}

${ }^{\mathrm{a}} \mathrm{P}<0.05$, statistical significance. $\mathrm{HR}$, hazard ratio; $\mathrm{CI}$, confidence interval.

expressing shPRKDC-2 which exhibited better knockdown was used in the following experiments. Cytotoxicity of 4 commonly used chemo-drugs was evaluated in these cells by performing dose response analysis. As shown in Fig. 4, stable knockdown of PRKDC sensitized MCF-7 cells to all the drugs. In addition, downregulation of PRKDC significantly reduced tumor growth rate as well as tumor weight in MCF-7 xenografted mice receiving 5-FU whereas injection of 5-FU alone had negligible effects on tumor growth or tumor weight (Fig. 5A and B). Immunohistochemical staining showed that 5-FU treatment led to more induction of cleaved caspase-3 in PRKDC knockdown xenografts compared with control xenografts (Fig. 5C). Collectively, the results showed that PRKDC directly regulates chemosensitivity of breast cancer cells both in vitro and in vivo by enhancing drug-induced apoptotic cell death. 

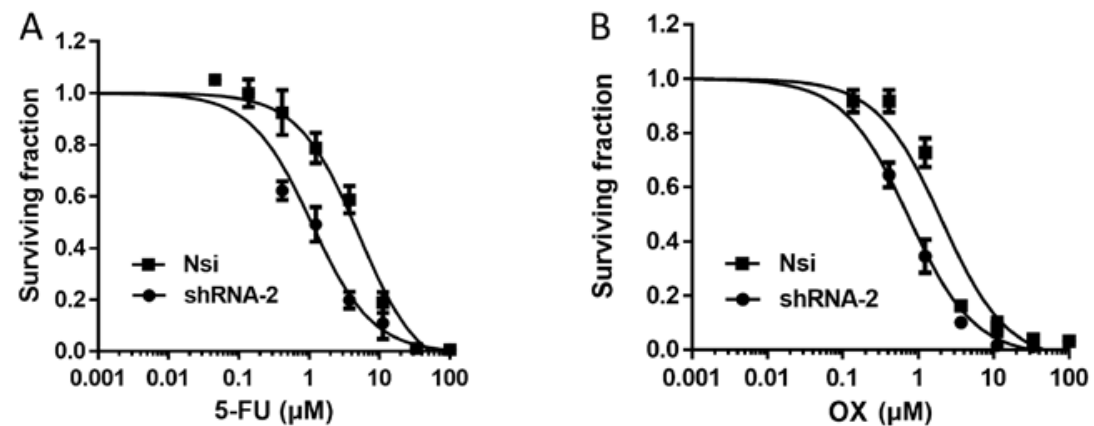

\begin{tabular}{|c|c|}
\hline shRNA & $\mathrm{IC}_{50}(\mu \mathrm{M})$ \\
\hline Nsi & $5.1 \pm 0.5$ \\
\hline shPRKDC-2 & $1.1 \pm 0.2$ \\
\hline
\end{tabular}

\begin{tabular}{|c|c|}
\hline shRNA & IC $_{50}(\mu \mathrm{M})$ \\
\hline Nsi & $2.0 \pm 0.3$ \\
\hline shPRKDC-2 & $0.7 \pm 0.06$ \\
\hline
\end{tabular}
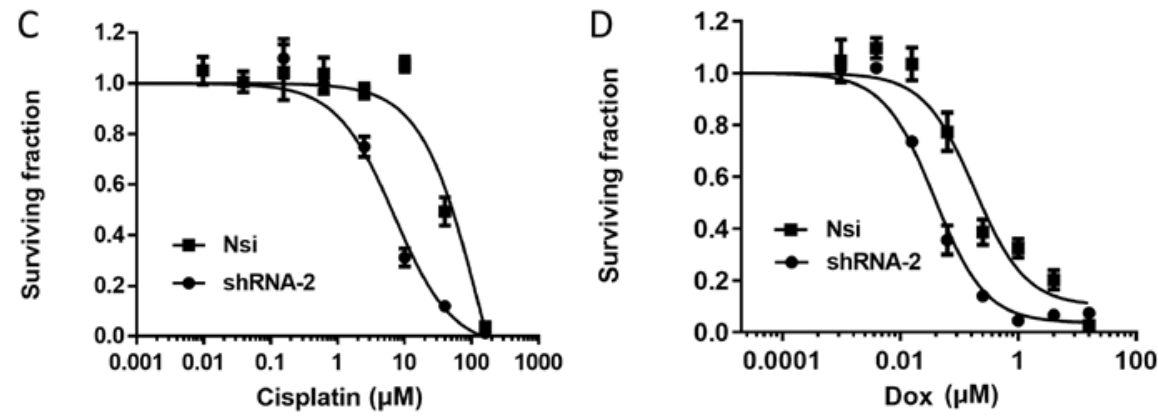

\begin{tabular}{|c|c|}
\hline shRNA & IC $_{50}(\mu \mathrm{M})$ \\
\hline Nsi & $48 \pm 5.3$ \\
\hline shPRKDC-2 & $7.0 \pm 1.1$ \\
\hline
\end{tabular}

\begin{tabular}{|c|c|}
\hline shRNA & IC $_{50}(\mu \mathrm{M})$ \\
\hline Nsi & $0.18 \pm 0.07$ \\
\hline shPRKDC-2 & $0.038 \pm 0.01$ \\
\hline
\end{tabular}

Figure 4. Downregulation of PRKDC sensitized breast cancer cells to chemo-drugs in vitro. Dose response curves of 5-FU (A), OX (B), Cisplatin (C), Dox (D) in MCF-7 cells expressing non-silencing shRNA or shRNA-2 targeting PRKDC. Data represent mean \pm SD, n=3. Nsi, non-silencing; 5-FU, 5-fluouracil; OX, oxaliplatin; Dox, doxorubicin
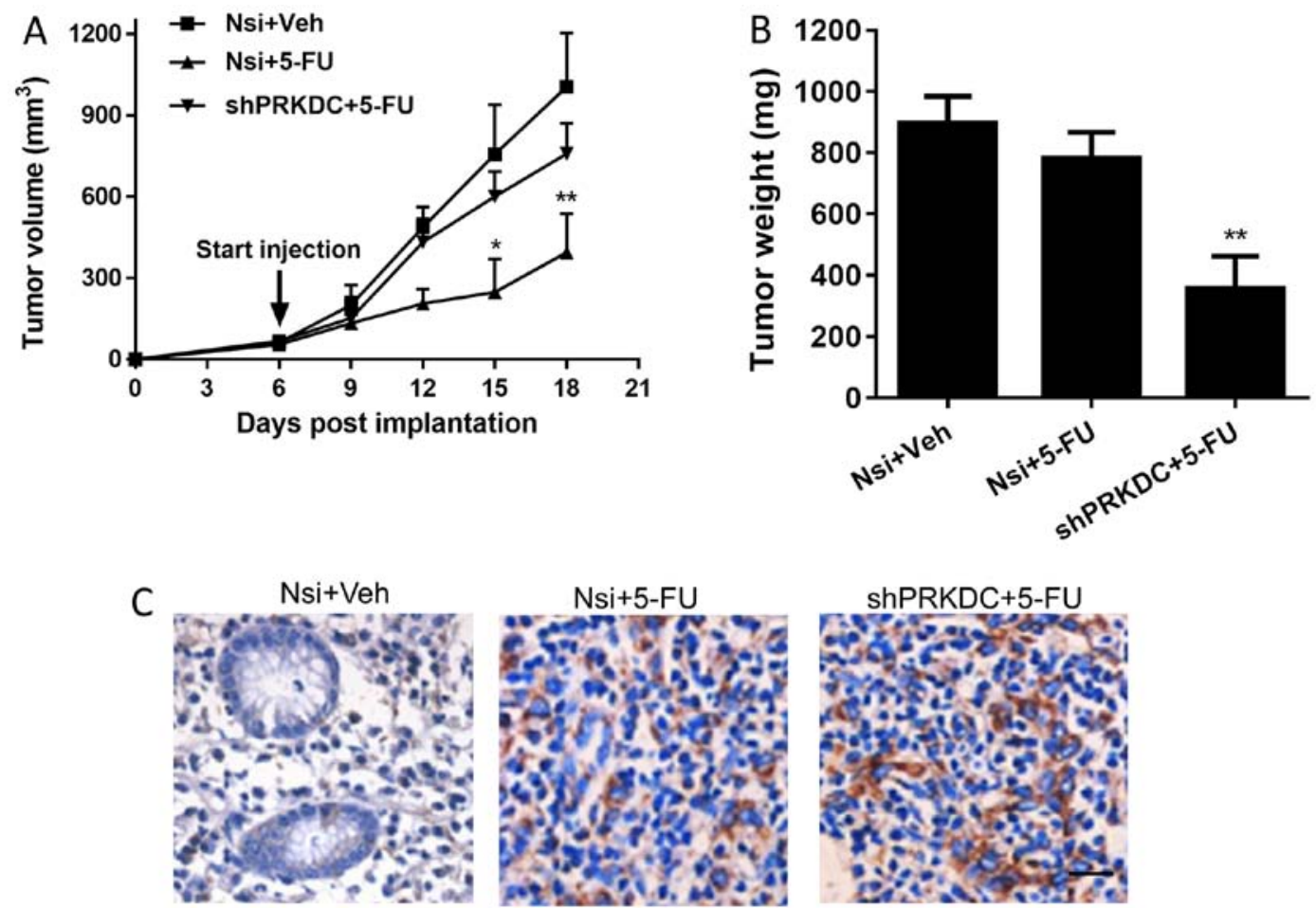

Figure 5. Downregulation of PRKDC sensitizes breast cancer cells to chemo-drugs in vivo. (A) Tumor growth curves of MCF-7 cells expressing non-silencing shRNA, shRNA aginst PRKDC with or without receiving 5-FU. Five mice were used in each group. ${ }^{*} \mathrm{P}<0.05 ;{ }^{* *} \mathrm{P}<0.01$. (B) Tumor weights of xenografts derived from the 3 groups as described above. ${ }^{* *} \mathrm{P}<0.01$. (C) Representative images of immunohistochemical staining for cleaved caspase 3 . Scale bar, $50 \mu \mathrm{M}$. 


\section{Discussion}

PRKDC, a serine/threonine-protein kinase, is a member of the phosphatidylinositol 3-kinase-related kinase (PIKK) family and is abundantly expressed in almost all mammalian cells (14). It forms the DNAPK complex with DNA-binding Ku70/80 heterodimer which serves as a key regulator of the non-homologous end-joining (NHEJ) pathway (15). Additionally, PRKDC plays an important role in maintaining proper cell cycle progression by coordinating mitosis, microtubule dynamics and chromosomal segregation and has been shown to prevent mitotic catastrophe after ionization $(9,16,17)$. Interestingly, both up- and down-regulation of PRKDC have been observed in various cancer types. For example, loss of PRKDC expression was found in gastric cancer, and was associated with advanced tumor stage, lymphatic invasion, lymph node metastasis and poor patient survival (18). Moreover, loss of PRKDC expression was shown to be predictive markers for poor prognosis of patients with gall bladder malignancies (19). On the other hand, PRKDC has been found to be upregulated associated with advanced clinical stages and poor prognosis in numerous tumor types (20-22). An elevated expression of PRKDC has been observed in esophageal cancer tissues compared with adjacent normal mucosae (21). High tumor/normal expression ratio of PRKDC is correlated with increased risk of death in non-small cell lung cancer (22). An increased expression of PRKDC was observed in highgrade lymphoma lymph node samples by staining compared with those from low-grade lymphoma patients (23). However, the expression of PRKDC and its association with clinicopathological factors has not been investigated in breast cancer patients. In our study, we observed significantly higher levels of PRKDC in tumor tissues compared with NATs in $72.9 \%$ of the patients analyzed (Fig. 1A) and the mean expression level difference was significant $(\mathrm{P}<0.01)$. In addition, PRKDC expression levels were significantly correlated with tumor grade, lymph node metastasis, and response to NAC (Table I). Moreover, the breast cancer patient with elevated levels of PRKDC showed significantly worse OS than those with low PRKDC expression (Fig. 2A). These results suggest that PRKDC may function as an oncogene in breast cancer tumorigenesis. The potential mechanism by which PRKDC regulates metastasis is through mediation of transcriptional network or through regulation of secreted proteins involved in migration and invasion $(24,25)$.

Due to its role in mediating DDR, aberrant expression/ activation of PRKDC has been associated with chemo- or radio-resistance $(26,27)$. A previous study showed that PRKDC regulated AKT activation and inhibited apoptosis in ovarian cancer cells with acquired platinum resistance $(28,29)$. In oral squamous cell carcinoma, a significant upregulation of PRKDC proteins was detected after radiotherapy in the residual cancer cells and this upregulation was associated with radioresistance (13). On the contrary, inhibition of PRKDC sensitized cancer cells to radiotherapy and chemotherapy $(27,30,31)$. For example, inhibition of PRKDC activity by a small molecule inhibitor, NU7441, sensitized breast cancer cells to ionizing radiation and doxorubicin (30). High expression of PRKDC was detected in glioma patients who were resistant to cisplatin-based chemotherapy and was shown to be a predictor for response to radiation therapy in esophageal cancer and early breast cancer $(12,32,33)$.

Our study suggested an association between PRKDC expression and chemosensitivity in breast cancer. We found that the expression of PRKDC was elevated in tissue samples from patients who do not respond to NAC compared to those who respond (Fig. 1B). There was a significant correlation between PRKDC expression level and chemosensitivity in these patients (Table I). In addition, high PRKDC expression level predicted poor survival in patients receiving NAC treatment (Fig. 2B). Moreover, multivariate analysis demonstrated that PRKDC was an independent prognostic factor for OS in breast cancer patients receiving NAC (Table II). Importantly, knockdown of PRKDC sensitized MCF-7 breast cancer cells to chemo-drugs in vitro and in vivo with increased induction of apoptosis (Figs. 4 and 5), demonstrating the direct involvement of PRKDC in regulating chemosensitivity in breast cancer cells. These results also highlight the potential of PRKDC as a drug target for chemosensitization or as an anti-cancer therapeutic strategy.

In summary, our study showed that PRKDC regulates chemosensitivity in breast cancer cells and its expression was significantly associated with chemoresistance in patients receiving NAC. PRKDC may serve as prognostic biomarker for poor survival and a predictor for NAC response in breast cancer patients. Further studies are warranted to understand the precise mechanism underlying the role of PRKDCs in regulation of chemosensitivity which may lend support to the development of new therapeutic strategies to overcome chemoresistance in breast cancer.

\section{Acknowledgements}

The present study was funded by Natural Science Foundation of China (NSFC grant no. 81360391) and Youth Science and Technology Innovative Talent Training Project of Xinjiang (grant no. 2014721043).

\section{References}

1. Siegel RL, Miller KD and Jemal A: Cancer statistics, 2016. CA Cancer J Clin 66: 7-30, 2016.

2. Cuzick J, Sestak I, Baum M, Buzdar A, Howell A, Dowsett M and Forbes JF; ATAC/LATTE investigators: Effect of anastrozole and tamoxifen as adjuvant treatment for early-stage breast cancer: 10-year analysis of the ATAC trial. Lancet Oncol 11: 1135-1141, 2010.

3. Perez EA, Romond EH, Suman VJ, Jeong JH, Davidson NE, Geyer CE Jr, Martino S, Mamounas EP, Kaufman PA and Wolmark N: Four-year follow-up of trastuzumab plus adjuvant chemotherapy for operable human epidermal growth factor receptor 2-positive breast cancer: Joint analysis of data from NCCTG N9831 and NSABP B-31. J Clin Oncol 29: 3366-3373, 2011.

4. Slamon D, Eiermann W, Robert N, Pienkowski T, Martin M, Press M, Mackey J, Glaspy J, Chan A, Pawlicki M, et al; Breast Cancer International Research Group: Adjuvant trastuzumab in HER2-positive breast cancer. N Engl J Med 365: 1273-1283, 2011.

5. Palmieri C and Jones A: The 2011 EBCTCG polychemotherapy overview. Lancet 379: 390-392, 2012.

6. Gonzalez-Angulo AM, Morales-Vasquez F and Hortobagyi GN: Overview of resistance to systemic therapy in patients with breast cancer. Adv Exp Med Biol 608: 1-22, 2007.

7. Jackson SP: DNA-dependent protein kinase. Int J Biochem Cell Biol 29: 935-938, 1997.

8. Goodwin JF and Knudsen KE: Beyond DNA repair: DNA-PK function in cancer. Cancer Discov 4: 1126-1139, 2014. 
9. Hsu FM, Zhang S and Chen BP: Role of DNA-dependent protein kinase catalytic subunit in cancer development and treatment. Transl Cancer Res 1: 22-34, 2012.

10. Zhang L, Komurov K, Wright WE and Shay JW: Identification of novel driver tumor suppressors through functional interrogation of putative passenger mutations in colorectal cancer. Int J Cancer 132: 732-737, 2013.

11. Zhang L, Kim S, Jia G, Buhmeida A, Dallol A, Wright WE, Fornace AJ, Al-Qahtani M and Shay JW: Exome sequencing of normal and isogenic transformed human colonic epithelial cells (HCECs) reveals novel genes potentially involved in the early stages of colorectal tumorigenesis. BMC Genomics 16 (Suppl 1): S8, 2015.

12. Mukherjee B, McEllin B, Camacho CV, Tomimatsu N, Sirasanagandala S, Nannepaga S, Hatanpaa KJ, Mickey B, Madden C, Maher E, et al: EGFRvIII and DNA double-strand break repair: A molecular mechanism for radioresistance in glioblastoma. Cancer Res 69: 4252-4259, 2009.

13. Shintani S, Mihara M, Li C, Nakahara Y, Hino S, Nakashiro K and Hamakawa H: Up-regulation of DNA-dependent protein kinase correlates with radiation resistance in oral squamous cell carcinoma. Cancer Sci 94: 894-900, 2003.

14. Hartley KO, Gell D, Smith GC, Zhang H, Divecha N, Connelly MA, Admon A, Lees-Miller SP, Anderson CW and Jackson SP: DNA-dependent protein kinase catalytic subunit: A relative of phosphatidylinositol 3-kinase and the ataxia telangiectasia gene product. Cell 82: 849-856, 1995.

15. Davis AJ, Chen BP and Chen DJ: DNA-PK: A dynamic enzyme in a versatile DSB repair pathway. DNA Repair (Amst) 17: 21-29, 2014.

16. Lee KJ, Lin YF, Chou HY, Yajima H, Fattah KR, Lee SC and Chen BP: Involvement of DNA-dependent protein kinase in normal cell cycle progression through mitosis. J Biol Chem 286 12796-12802, 2011

17. Shang ZF, Huang B, Xu QZ, Zhang SM, Fan R, Liu XD, Wang Y and Zhou PK: Inactivation of DNA-dependent protein kinase leads to spindle disruption and mitotic catastrophe with attenuated checkpoint protein 2 Phosphorylation in response to DNA damage. Cancer Res 70: 3657-3666, 2010.

18. Lee HS, Yang HK, Kim WH and Choe G: Loss of DNA-dependent protein kinase catalytic subunit (DNA-PKcs) expression in gastric cancers. Cancer Res Treat 37: 98-102, 2005.

19. Ren F, Yang ZL, Tan X, Liu D, Zou Q, Yuan Y, Li J, Liang L, Zeng $\mathrm{G}$ and Chen S: DNA-PKcs and Ku70 are predictive markers for poor prognosis of patients with gall bladder malignancies. Appl Immunohistochem Mol Morphol 22: 741-747, 2014.

20. Hosoi Y, Watanabe T, Nakagawa K, Matsumoto Y, Enomoto A, Morita A, Nagawa $\mathrm{H}$ and Suzuki N: Up-regulation of DNA-dependent protein kinase activity and Sp1 in colorectal cancer. Int J Oncol 25: 461-468, 2004.

21. Tonotsuka N, Hosoi Y, Miyazaki S, Miyata G, Sugawara K, Mori T, Ouchi N, Satomi S, Matsumoto Y, Nakagawa K, et al: Heterogeneous expression of DNA-dependent protein kinase in esophageal cancer and normal epithelium. Int J Mol Med 18: 441-447, 2006
22. Xing J, Wu X, Vaporciyan AA, Spitz MR and Gu J: Prognostic significance of ataxia-telangiectasia mutated, DNA-dependent protein kinase catalytic subunit, and Ku heterodimeric regulatory complex 86-kD subunit expression in patients with nonsmall cell lung cancer. Cancer 112: 2756-2764, 2008.

23. Holgersson A, Erdal H, Nilsson A, Lewensohn R and Kanter L: Expression of DNA-PKcs and Ku86, but not Ku70, differs between lymphoid malignancies. Exp Mol Pathol 77: 1-6, 2004.

24. Kotula E, Berthault N, Agrario C, Lienafa MC, Simon A, Dingli F, Loew D, Sibut V, Saule S and Dutreix M: DNA-PKcs plays role in cancer metastasis through regulation of secreted proteins involved in migration and invasion. Cell Cycle 14: 1961-1972, 2015.

25. Goodwin JF, Kothari V, Drake JM, Zhao S, Dylgjeri E, Dean JL, Schiewer MJ, McNair C, Jones JK, Aytes A, et al: DNA-PKcsmediated transcriptional regulation drives prostate cancer progression and metastasis. Cancer Cell 28: 97-113, 2015.

26. Burdine LJ, Burdine MS, Moreland L, Fogel B, Orr LM, James J, Turnage RH and Tackett AJ: Proteomic identification of DNA-PK involvement within the RET signaling pathway. PLoS One 10: e0127943, 2015.

27. Elliott SL, Crawford C, Mulligan E, Summerfield G, Newton P, Wallis J, Mainou-Fowler T, Evans P, Bedwell C, Durkacz BW, et al: Mitoxantrone in combination with an inhibitor of DNA-dependent protein kinase: A potential therapy for high risk B-cell chronic lymphocytic leukaemia. Br J Haematol 152: 61-71, 2011.

28. Stronach EA, Chen M, Maginn EN, Agarwal R, Mills GB, Wasan $\mathrm{H}$ and Gabra H: DNA-PK mediates AKT activation and apoptosis inhibition in clinically acquired platinum resistance. Neoplasia 13: 1069-1080, 2011.

29. Vivanco I and Sawyers CL: The phosphatidylinositol 3-Kinase AKT pathway in human cancer. Nat Rev Cancer 2: 489-501, 2002.

30. Ciszewski WM, Tavecchio M, Dastych J and Curtin NJ: DNA-PK inhibition by NU7441 sensitizes breast cancer cells to ionizing radiation and doxorubicin. Breast Cancer Res Treat 143: 47-55, 2014.

31. Munck JM, Batey MA, Zhao Y, Jenkins H, Richardson CJ, Cano C, Tavecchio M, Barbeau J, Bardos J, Cornell L, et al: Chemosensitization of cancer cells by KU-0060648, a dual inhibitor of DNA-PK and PI-3K. Mol Cancer Ther 11: 1789-1798, 2012.

32. Noguchi T, Shibata T, Fumoto S, Uchida Y, Mueller W and Takeno S: DNA-PKcs expression in esophageal cancer as a predictor for chemoradiation therapeutic sensitivity. Ann Surg Oncol 9: 1017-1022, 2002.

33. Söderlund Leifler K, Queseth S, Fornander T and Askmalm MS: Low expression of Ku70/80, but high expression of DNA-PKcs, predict good response to radiotherapy in early breast cancer. Int J Oncol 37: 1547-1554, 2010. 